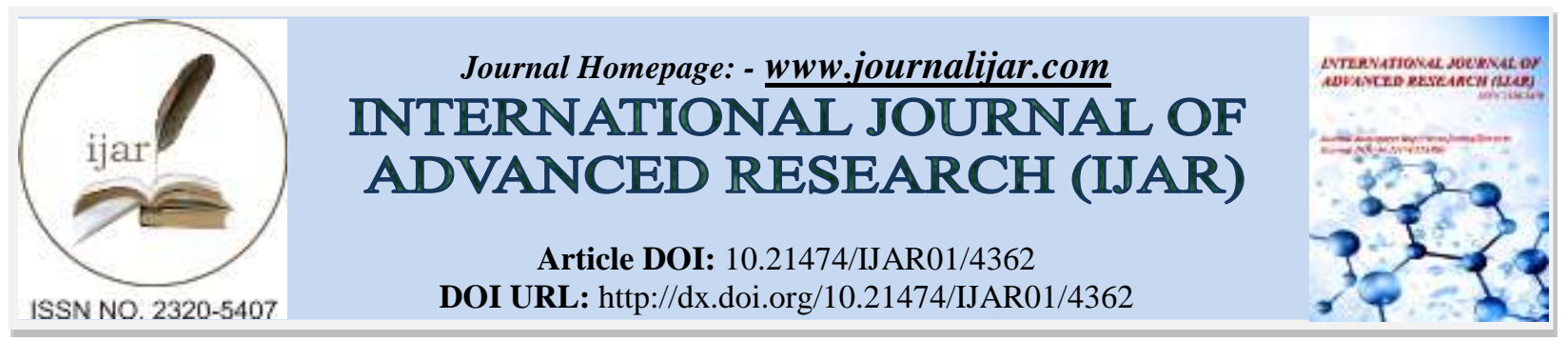

RESEARCH ARTICLE

\title{
ROLE OF PERSONAL ADVANCED TO NURSE PERFORMANCE IMPROVEMENT: TASK PERFORMANCE AND CONTEXTUAL PERFORMANCE
}

Achmad Zakaria $^{1}$, Tjipto Suwandi ${ }^{2}$ and Rahmat Hargono ${ }^{3}$.

1. Doctoral Program of Health Science, Faculty of Public Health, Airlangga University, Indonesia.

2. Department of Occupational Health, Faculty of Public Health, Airlangga University, Indonesia.

3. Department of Health Promotion \& Behavioral Science, Faculty of Public Health, Airlangga University, Indonesia.

\section{Manuscript Info}

-........................

Manuscript History

Received: 23 March 2017

Final Accepted: 26 April 2017

Published: May 2017

Key words:-

Nurse, Personal advanced, Task

performance, Contextual performance

\section{Abstract}

The implication of low patient satisfaction on nursing service is resulted from the low performance attribute of nursing service. This low performance improvement is the focus of efforts to increase patient satisfaction. Empirical facts suggest that the nurse's performance weakness is related to interpersonal behavior. The interpersonal competence of the nurse is a character of the unconsciousness, the result of past learning is identified as a personal ability called "Personal Advanced". The main purpose of this research is to prove the influence of advanced personal to the performance of task and the contextual performance of the nurse. The survey was conducted on respondents covering 195 nurses at RSUD Jombang which was selected by proportional random sampling method. In addition, the study also involved 390 patients to assess nurse performance. All participants were required to complete the advanced personal measurement scale developed from Peter Senge and the nurse's performance scale developed from Greenslade \& Jimmison. By using regression test, it is found that there is a positive and significant relationship between personal advanced (personal vision, creative tension, structural conflict, self-regulation, situation awareness) on nurse performance both performance and contextual performance.

Copy Right, IJAR, 2016,. All rights reserved.

\section{Introduction:-}

Most experts such as Campbell (1990); Viswesvaran (1993); Griffin MA (2008), Wisecarver MM (2007); Kamali N. J and Abbas M. Y (2012); Bogaert P.V (2013); Pitt V, et al (2012) argue that the performance concerns the work that is an element of a specific job. Although these differ in their degree of specificity, the similarities observed between the dimensions of individual work performance are described in the framework. Task performance can be defined as the ability (i.e., competence) in which the performance ability is the core task of the job (Campbell JP, 1990). Other labels sometimes used for task performance are special task capabilities, Griffin MA (2008) and Wisecarver MM (2007). While Greenslade J.H and Jimmieson N. L (2011) developed a valid scale to measure work performance, based on a task performance model. Performance of tasks consists of four dimensions: the provision of 
information, coordination of care, provision of support and technical care. Patient-centered outcomes measures, nursing centered intervention measures, centered measurement systems (Christopher A \&Van Fosson CA, 2016) .

Performance is not only limited to what is the core task in a job but can also be seen based on contextual work. Borman and Motowidlo (1993); Griffin MA.2007); Wisecarver MM, (2007); and Fluegge ER (2009) posit performance ideas contextually that include certain non-job behaviors such as cooperation, dedication, enthusiasm and persistence and are distinguished from task performance that includes specific work behaviors. This opinion is supported by Fletcher (2001) who mentions that contextual performance with attributes goes beyond task competence and foster behavior improves the climate and organizational effectiveness. Kushnira T (2008) states that the contextual performance of nurses can be measured based on the level of participation in nursing services. While, Kaur D (2015) addes one aspect of caring behavior is as a contextual performance. Sony M (2016) completes the contextual performance with incorporating good interpersonal behavior. Meanwhile, Greenslade JH and Jimmieson N. L (2011) explaines that the nurse's contextual performance includes dimensions: (1) Job-task support, (2) Interpersonal support, (3) Compliance, (4) Volunteering for additional duties.

Determinant factors that affect performance are personal attributes, work effort, and organizational support (Blumberg \& Pringle, 1982). Empirical facts state that the weakness of nurse performance is in nursing service which is related to interpersonal behavior which in this case according to Kaur D (2015) is called as caring behavior. These three determinants of performance above have not been able to prove significantly changes in interpersonal behavior of nurses. Nurses are required to continue to learn to develop the skills and competencies possessed in achieving the vision that has been determined. An ability to manage their thoughts, wants and potentials to always seek ways to continue to grow and be able to control the attention, emotions, and actions necessary through the process of identifying and understanding the meaning of information as a projection of appropriate action intervention is called "Personal Advanced" (Marquardt MJ, 2002); (Sayers, 2013). A nurse who has a high personal advanced always wants to get new things to learn, to develop new concepts is a way of life that emphasizes the development and satisfaction in personal and professional life. Kuşcu Z K, et al (2015); Pham L B, et al, (2001); Carpiano R M \& Kimbro RT (2012); and Ang S \& Malhotra R (2016) affirm that learning as the ability to produce truly desired results in life and the extent to which individuals are able to adapt to unforeseen or uncontrollable conditions.

Personal Advanced has six main pillars that include: personal vision, creative tension, strict conflict, self regulation, and situation awareness. Personal vision is an important factor in a person if you have a clear and firm vision (Tsai Y, 2011). Vision is the mental image of the desired future that has not been achieved, regularly appeared in the flow of thought and developed by the individual Strasser A (2011). Personal vision is a ability to focus on the intrinsic desires and will naturally commit to achieve. They are full of energy and enthusiasm (Senge P, 1990). A person who has a high personal vision has an orientation to the vision as follows: a real understanding of vision; care and commitment to achieve; enthusiastic and full of energy; and have courageous attitude to vision. Creative tension, according to Senge P (1994), is a creative energy source that arises as a result of the gap between current vision and reality and uses the gap to generate energy. The gap is a source of creative energy. According to Scherer R \& Gustafssona JE (2015), creative energy consists of a number of skills on the problem-solving process of various types of problems. Resources that demonstrate a general ability creatively use objects intelligently in problem solving (Olteteanu A M \& Falomir Z, 2015). The structural conflict, according to Senge P (1990), is a belief in the inadequacy to achieve what is truly desired. If a person has faith in helplessness, then systemically works strongly against the creativity they have. Structural conflict is essentially an intrapersonal conflict that Schermerhorn J R (2002) describes as the actual or perceived pressure of incompatible objectives. Structural conflicts can only be changed by changing beliefs in inability and inadequacy, through commitment to the truth and using the subconscious.

Furthermore, self-regulation is conceptualized as encompassing three sub-processes: self-observation, selfjudgment, and self-reaction (Schunk DH \& Zimmerman BJ, 2003). According to Paulo A. et al (2016), selfregulation refers to skills and processes related to the direction, planning, and control of attention and / or cognition, emotion, and behavior or action required for optimal adaptive function. Meanwhile, Ursache, Blair, \& Raver, (2012) states that self-regulation such as executive function (EF) and emotion regulation (ER) is essential for successful learning. Situation awareness has become one of the most important non-technical skills that requires a person to perform tasks (Mitchell and Flin, 2008; Korkiakangasas, 2014). Knowing what is happening to the surrounding environment (Endsley, M.R., 2000) and displaying awareness of the events around them: this is often beyond 
consciousness (Gillespie et al., 2010). Self-regulation is composed of three levels: perception of cues, comprehension of their meaning, and projection of their status for the near future (Endsley, 2000).

\section{Methods:-}

This research was ex post facto study, with type of descriptive analytic research that is research directed to explain a condition or situation with quantitative data collection for hypothesis testing. The study was conducted in the inpatient room at a hospital in Jombang in the month of October 2016. Population was all nurses implementing the role and function of nursing service in the in-patient room which amounted to 368 . The sample size in this study was 195 nurses and 380 patients selected using proportional random sampling technique. Work and contextual performance measurements using work-scale and contextual scales are developed from Greenslade J.H, 2011 and Koopmans L, 2011. Task performance consists of 4 areas and 20 items, which includes provision of information $(7$ items), technical care ( 5 items), provision of support ( 5 items), and coordination of care ( 3 items). Meanwhile, the contextual performance measurement consists of 4 areas and 14 items, which includes job-task support (3 items), interpersonal support (5 items), discipline ( 2 items), leadership and managerial (4 items). While for personal advanced measurement is measured by using advanced personal measurement scale developed from Senge, P.M. (1990); Geokçearslan S (2016) and Endsley, M.R., (2000). Personal advanced consists of 5 areas and 54 items, which includes personal vision (13 items), creative tension (12 items), structural conflict (12 items), self regulation (10 items), situation awareness (7 items). Result of validity test using Spearman's analysis Cronbach'- $\alpha=5 \%$., Df $=$ $28, \mathrm{r}$ table $=0,361,34$ item of performance appraisal valid. Meanwhile, reliability test results obtained by Alpha Cronbach value of 0,501 , there are 54 items of statement otherwise reliable.

\section{Results:-}

\section{Description of Research Variables:-}

The mean value, standard deviation and correlation between the variables in this study can be seen in table 1 . The results of personal advanced dimension correlations including personal vision, creative tension, conflict structural, self regulation, and overall situation awareness are related to task performance. Furthermore, personal advanced is also significantly related to contextual performance which can be seen in table 1 of all personalized dimensions fully related to contextual performance.

Table 1:- Mean, standard deviation, simple correlation among study variables

\begin{tabular}{|l|l|l|l|l|}
\hline \multicolumn{1}{|c|}{ Personal Advanced } & Mean & SD & Task Performance & Contextual Performance \\
\hline Personal Vision & 38,07 & 3,58 & $0,017^{*}$ & $0,005^{*}$ \\
Creative Tension & 34,75 & 5,05 & $0,035^{*}$ & $0,0001^{*}$ \\
Conflict Structural & 34,62 & 4,11 & $0,001^{*}$ & $0,014^{*}$ \\
Self Regulation & 28,60 & 2,32 & $0,011^{*}$ & $0,015^{*}$ \\
Situation Awareness & 20,38 & 2,07 & $0,217^{*}$ & 0,004 \\
Task Performance & 92,60 & 11,80 & - & - \\
Contextual Performance & 68,44 & 6,76 & - & - \\
\hline
\end{tabular}

The role of personal advanced to task performance:-

Table 2 shows that when the performance of the task is made as a criterion variable in the regression equation, there are still five personal advanced contained in the task performance equation. There are variables that have the highest multiple correlation value that is structural conflict variable with correlation coefficient of 0,237 with $\boldsymbol{R}^{2}=0,056$, it can be explained that $5,6 \%$ of job performance is explained by structural conflict. Furthermore, the results show that personal vision $(\beta=0.171)$, creative tension $(\beta=0.128)$, structural conflict $(\beta=0.237)$ self regulation $(\beta=0.181)$, situation awareness $(\beta=0.157)$ generally have a role in explaining the performance of nurse duties.

Table 2:- Multiple Regressions Results Testing of Personal Advanced To Task Performance

\begin{tabular}{|l|l|l|l|l|l|l|}
\hline Personal Advanced & Multiple Correlation & $\boldsymbol{R}^{2}$ & $\mathbf{B}$ & $\boldsymbol{\beta}$ & $\mathbf{t}$ & Sig \\
\hline Personal Vision & 0,171 & 0,029 & 0,563 & 0,171 & 2,410 & 0,017 \\
Creative Tension & 0,128 & 0,024 & 0,299 & 0,128 & 1,171 & 0,036 \\
Structural & 0,237 & 0,056 & 0,680 & 0,237 & 3,391 & 0,001 \\
Conflict & 0,181 & 0,033 & 0,919 & 0,181 & 2,651 & 0,011 \\
Self Regulation & 0,157 & 0,027 & 0,341 & 0,157 & 2,231 & 0,021 \\
Situation Awareness & 0,157 & & & & & \\
\hline
\end{tabular}


Meanwhile, the result of test about the role of personal advanced component toward contextual performance showed that the structural conflict had the greatest role to the contextual performance of nurse with $\boldsymbol{R}^{2}=0,072$ which can be explained that the contextual performance of the nurse is influenced by the creative tension of $7.2 \%$. All of the predictor variables in the contextual model of contextual performance are entirely valid for the contextual performance of the nurse. Furthermore, multiple regression test results obtained by personal vision $(\beta=0,202)$, creative tension $(0,268)$, structural conflict $(0,175)$, self regulation $(1,73)$ situation awareness $(0,203)$ overall vaiabel is a valid predictor to nurse contextual performance .

Table 3:- Multiple Regression Results of Personal Advanced To Task Performance

\begin{tabular}{|l|c|c|c|c|c|c|}
\hline & Multiple Correlation & $\boldsymbol{R}^{2}$ & $\mathbf{B}$ & $\boldsymbol{B}$ & $\mathbf{t}$ & Sig \\
\hline Personal Vision & 0,202 & 0,041 & 0,382 & 0,202 & 2,872 & 0,005 \\
Creative Tension & 0,268 & 0,072 & 0,358 & 0,268 & 3,864 & 0,0001 \\
Conflict Structural & 0,175 & 0,031 & 0,288 & 0,175 & 2,474 & 0,014 \\
Self Regulation & 0,173 & 0,030 & 0,504 & 0,173 & 2,447 & 0,015 \\
Situation Awareness & 0,203 & 0,041 & 0,661 & 0,203 & 2,885 & 0,004 \\
\hline
\end{tabular}

Thus, personal advanced which includes personal vision, creative tension, conflict structural, self regulation, and situation awareness in addition is a predictor of task performance is also a predictor of the contextual performance of nurses.

\section{Discussion:-}

The use of Personal Advanced as a predictor of the task and contextual performance of nurses is an attempt to explain the performance of nurses who are oriented towards improving patient satisfaction with nursing services. The relationship between personal advanced to performance has not been much of a study, many researchers focus on the development of individual attributes (Johnson and Cowin, 2013, Schmidt and MacWilliams, 2011), motivational factors (Campbell et al., 1993), organizational support (Dakhakhny A. M., 2010), and educational program (Platisa Ch, et al, 2015 and Jacobs R, et al 2013). As explained by Senge P (1994), part of the personal advanced that is personal vision, creative tension and structural conflict is the ability of one's self-development process continuously always looking for ways to keep developing, to get new things to learn, and to make changes. The purpose of this study is to explain the relationship of personal advanced role to the performance of nurses both performance task and contextual performance. The results show that all positive personal dimensions are significantly related to the task and contextual performance of the nurse. The relationship is based on a change that emphasizes more progress and satisfaction in personal and professional life (Sayers, 2013). Personal and professional life concerning nurse internal changes in the form of improvement of knowledge, attitude and behavior depicts a dignified nurse. According to Senge P. M. (1994) states that if someone has a personal vision, creative tension and structural conflict will have a high performance. Paulo A. Graziano PA, Hart K. (2016) explains that self regulation skills can increase willingness to learn. In addition, Basol G \& Balgamis E. (2016) adds that self regulation is a key factor in the success of learning as it provides nurses to organize their learning through improved knowledge, skills and attitudes. Meanwhile, situational awareness places emphasis more on non-technical capabilities such as the ability to identify the process and understand the essential elements of information about what is happening.

Another purpose of this study is to determine the most important factors of personal advanced that affect the performance of the task and contextual nurses. Based on the results of this study found that the most important factor of personal advanced that affect the performance of tasks is structural conflict. Structural conflict, according to Senge P (1994) is defined as a voltage that is opposed to creative stress. The stress is a belief in powerlessness. Nurses who are able to overcome their helplessness can be seen from the manifestation of the nurse's ability to commit to the truth by starting to deal with structural conflict by telling the truth. Next is his ability to accomplish extraordinarily complex tasks with elegance and ease, using the subconscious mind. Thus, if the nurse is able to overcome his belief in the helplessness and feasibility, the nurse confidently carries out the task to achieve the success of the task. As given the performance of the task is a special skill of a job or special nursing performance capabilities performed by nurses in providing care nursing both direct care and indirect care. Nurses who have high confidence in their ability will be able to carry out provision of information, technical care, provision of support, and coordination of care (Greenslade J.H and Jimmieson N. L, 2011; Al-Homayan, et al, 2013). Furthermore, creative stress that is a dimension of best personal advanced predicts contextual performance. Creative energy arises from the gap between personal vision and reality. According to Scherera R \& Gustafssona JE (2015) creative energy consists 
of a number of skills on the problem-solving process of various types of problems. Thus, this creative tension becomes important in supporting nurse duties. The creative nurse will certainly be able to adapt well to the condition of the work environment and be able to perform tasks beyond the main task. As explained by Greenslade \& Jimmieson (2011), it is termed as an extra role behavior. Greenslade states that if nurses can create a service climate through nursing technical and extra-role behaviors well, in turn the efforts provided by nurses are predicted to increase patient satisfaction.

\section{Conclusion and Suggestion:-}

Based on the results of the research and discussion above, it can be concluded that:

1. Personal advanced effects significantly to nurse performance. Personal advanced can generate, direct and affect the capability to maintain and improve performance.

2. Structural conflict is an advanced personal dimension that affects task performance well. The ability of the nurse to overcome his helplessness has a commitment to the truth with full confidently to accomplish the main task well.

3. Best creative tension of personal advanced dimension influences contextual performance. Creative energy consists of a number of skills on the problem-solving process so it is possible to complete the main task.

Suggestions for the hospital, it is expected to able to improve the nurse performance that focuses on patient satisfaction. The hospital should be not only prioritizing nurse performance improvement through improving nurse ability, work effort and organizational support but also considering efforts to improve personal advanced. Furthermore, in the nursing care program that refers to personal advanced done with full awareness is better done repeatedly to enable automatic capabilities on the subconscious.

\section{References:-}

1. Al-Homayan AM, Subramaniam C, Shamsudin FM., Islam R., (2013). Impacts of Job Performance Level on Nurses in Public Sector Hospitals, American Journal of Applied Sciences 10 (9): 1115-1123, 2013.

2. Ang S,, Rahul Malhotra (2015), Association of received social support with depressive symptoms among older males and females in Singapore: Is personal mastery an inconsistent mediator?, Social Science \& Medicine 153 (2016) 165e173, journal homepage: www.elsevier.com/locate/socscimed.

3. Basol G \& Balgamis E, (2016), A multivariate investigation of gender differences in the number of online tests received-checking for perceived self-regulation, Computers in Human Behavior 58 (2016) 388e397, journal homepage: www.elsevier.com/locate/comphumbeh

4. Bogaert PV, Clarke S, Wouters K, Franck E, William R, Mondelaers M., (2013), Impacts of unit-level nurse practice environment, workload and burnout on nurse-reported outcomes in psychiatric hospitals: A multilevel modelling approach, International Journal of Nursing Studies 50 (2013) 357-365, journal homepage: www.elsevier.com/ijns

5. Borman, W C \& Motowidlo, S J (1993) Expanding the criterion domain to include elements of contextual performance, in Handbook of Human Resource Management, ed N Schmitt and W C Borman, Jossey-Bass, San Francisco

6. Campbell CH, Ford P, Rumsey MG (1990). Development of multiple job performance measures in a representative sample of jobs. Pers Psychol.1990;43:277-300.

7. Carpiano R M \& Kimbro RT, (2012), Neighborhood Social Capital, Parenting Strain, and Personal Mastery among Female Primary Caregivers of Children, Journal of Health and Social Behavior 53(2) 232- 247 () American Sociological Association 2012.

8. Endsley, M.R., (2000). Direct measurement of situation awareness: validity and use of SAGAT. In: Endsley, M.R., Garland, D.J. (Eds.), Situation Awareness Analysis and Measurement. Lawrence Erlbaum, Mahwah, NJ, pp. $147-173$

9. Fletcher, C (2001) Performance appraisal and management: the developing research agenda, Journal of Occupational and Organizational Psychology, 74 (4), pp 473-87

10. Fluegge ER (2009). Who put the fun in functional? Fun at work and its effects on job performance. Dissertation Abstr Int Sect A Hum Soc Sci. 2009;69:2781.

11. Gillespie B.M, Chaboyer W., Longbottom P, Wallis, M, (2010). The impact of organisational and individual factors on team communication in surgery: a qualitative study. International Journal of Nursing Studies 47 (6) $732-741$. 
12. Greenslade JH \& Jimmieson NL (2011), Impact of an educational program on nurses'performance toward children in Thomas traction, International Journal of Orthopaedic and Trauma Nursing (2010) 14, 206-219.

13. Griffin MA, Neal A, Parker SK (2007) A new model of work role performance: positive behavior in uncertain and interdependent contexts. Acad Manag J. 2007;50:327-347.

14. Jacobs R, Mannion R, Davies H. TO, Harrison S, Konteh F. Walshe K(2013), The relationship between organizational culture and performance in acute Hospitals, Social Science \& Medicine 76 (2013) 115e125

15. Johnson, M., Cowin, L., (2013). Measuring the qualities of nurses: development and testing of the qualities of nurses scale. Nurs. Educ. Perspect. 34 (2), 111-117. http:// dx.doi.org/10.5480/1536-5026-34.2.111.

16. Kamali NJ \& Abbas MJ (2012), Healing Environment: Enhancing Nurses' Performance through Proper Lighting Design, Procedia - Social and Behavioral Sciences 35 ( 2012 ) $205-212$.

17. Kaur D, Sambasivan M, Kumar N (2015). Impact of emotional intelligence and spiritual intelligence on the caringbehavior of nurses: a dimension-level exploratory study among publichospitals in Malaysia, 28 (2015) 293-journal homepage: www.elsevier.com/locate/apnr

18. Korkiakangas T, Weldon SM , Bezemer J , Kneebone R (2014), Nurse-surgeon object transfer: Video analysis of communication and situation awareness in the operating theatre, International Journal of Nursing Studies 51 (2014) 1195-1206, journal homepage: www.elsevier.com/ijns

19. Kuşcu Z K, Yener M, Gürbüz FG (2015), Learning Organization and its Cultural Manifestations: Evidence from a Global White Goods Manufacturer, Procedia - Social and Behavioral Sciences 210 ( 2015 ) $154-163$

20. Kushnira T, Ehrenfelda M, Shalisha Y, (2008), The effects of a coaching project in nursing on the coaches'training motivation, training outcomes, and job performance: An experimental study, International Journal of Nursing Studies 45 (2008) 837-845

21. Marquardt, Michael J. (2002). Building The Learning Organization: Mastering The 5 Element for Corporate Learning. United States of America. Davies-Black Publishing, Inc

22. Mitchell L, Flin R., (2008). Non-technical skills of the operating theatre scrub nurse: literature review. Journal of Advanced Nursing 63 (1) 15-24.

23. Olteteanu A.M \& Falomir Z, (2016). Object replacement and Object composition in a creative cognitive system. Towards to a computational solver of the alternative uses test. Cognitive Systems Reseach 39 (2016) 15-32. www.elsever.com

24. Paulo A, Graziano PA, Hart K., (2016). Beyond behavior modification: Benefits of social-emotional/selfregulation training for preschoolers with behavior problems, Journal of School Psychology 58 (2016) 91-111,

25. Pham L B, Taylor SE, Seeman TE.,(2001). Effects of Environmental Predictability and Personal Mastery on Self-Regulatory and Physiological Processes, PSPB, Vol. 27 No. 5, May 2001 611-620 () 2001 by the Society for Personality and Social Psychology, Inc.

26. Pitt PV, Powis D, Tracy Levett-Jones T, Hunter S., (2012), Factors influencing nursing students' academic and clinical performance and attrition: An integrative literature review, Nurse Education Today 32 journal homepage: www.elsevier.com/nedt (2012): 903-913.

27. Platisa Ch \& Zimeras RS (2015), Relation between job satisfaction and job performance in healthcare Services, Procedia - Social and Behavioral Sciences 175 ( 2015 ) 480 - 487

28. Sayers, Fran (2013). Personal Mastery. [Online] available at www.opi-inc.com/personal. [Accessed May, 20 2016]

29. Scherer R \& Gustafssona JE (2015). The Relations Among Openness, and performance in creative Problem Solving: A Substantive-Methodological Approach, Thinking Skills and Creativity 18 (2015) 4-17. www. Elsevier .com.

30. Schermerhorn JR (2002), Organizational Behavior, 7TH edition, Copyright 2002 @ John Wiley \& Sons, Inc. All rights reserved. Printed in the United States of America.

31. Schmidt, B., MacWilliams, B., (2011). Admission criteria for undergraduate nursing programs: a systematic review. Nurse Educ. 36 (4), 171-174.

32. Schunk DH \& Zimmerman BJ, (2003). self regulation and learning, Handbook of Psychology, Vol. 7 Educational Psychology, William M. Reynolds, Gloria E. Miller Volume Editors, John Wiley \& Sons, Inc.

33. Senge,P.M. (1990). The Fifth Discipline: The art and the practice of learning organization. [online] available at www.4grantwriters.com [accessed march, 10 2013]

34. Senge, P.M., Roberts, C., Ross, R.B., Smith, B.J., Kleiner, A., (1994). The Fifth Discipline Fieldbook. Doubleday Publ., New York.

35. Sony M \& Mekoth N (2016), The relationship between emotional intelligence, frontline employee adaptability, job satisfaction and job performance, Journal of Retailing and Consumer Services 30(2016)20-32. 
36. Strasser A (2011), The relevance of mental images: Personal visions bridge the gap between implicit motives and personal goals. Genehmighten Dissertation Lehrstuhl für Psychologie, Technische Universitat Munchen.

37. Tsai Y (2011). Relationship between Organizational Culture, Leadership Behavior and Job Satisfaction, BMC Health Serv Res. 2011; 11: 98.

38. Ursache, A., Blair, C., \& Raver, C., (2012). The promotion of self-regulation as ameans of enhancing school readiness and early achievement in children at risk for school failure. Child Development Perspectives, 6, 122128.

39. Van Fosson, CA (2016), Unfinished nursing care: An important performance measure for nursing care systems, Nurs Outlook 64 ( 201 6) 12 4e 13 6http:// doi.org/10.1016/j.outlook.2015.12.010. The University of Texas at Austin School of Nursing, San Antonio, TX

40. Viswesvaran C, (1993). Modeling Job Performance: Is There a General Factor? [PhD dissertation]. Iowa City: The University of Iowa; 1993.

41. Wisecarver MM, Carpenter TD, Kilcullen RN (2007). Capturing interpersonal performance in a latent performance model. Milit Psychol. 2007;19:83-101. 